\title{
Acute Toxicity of Paclitaxel Based Dose Dense and Conventional Neoadjuvant Chemotherapy in Locally Advanced Female Breast Cancer Patients
}

\author{
Nonam Chellappan ${ }^{1}$, Smitha G. Raj² \\ ${ }^{1}$ Department of Radiotherapy, Government T.D. Medical College, Alappuzha, Kerala, India. \\ ${ }^{2}$ Department of Anatomy, Government T.D. Medical College, Alappuzha, Kerala, India.
}

\section{ABSTRACT}

\section{BACKGROUND}

Breast cancer is a systemic disease that requires treatment with surgery, chemotherapy, radiation, endocrine therapy and biological therapy. Neoadjuvant chemotherapy is the recent treatment of locally advanced breast cancer. The purpose of this study was to assess the acute toxicity of paclitaxel-based dose-dense and conventional neoadjuvant chemotherapy in locally advanced female breast cancer patients.

\section{METHODS}

In this study, neoadjuvant paclitaxel was given to a hundred locally advanced breast malignancies of female patients. Three weekly paclitaxel $200 \mathrm{mg} / \mathrm{m}^{2}$ ( 4 courses) was given for fifty patients and weekly paclitaxel $80 \mathrm{mg} / \mathrm{m}^{2}$ (10 courses) was given for fifty patients along with four-course of three weekly doxorubicin $50 \mathrm{mg} / \mathrm{m}^{2}$ given in both arms. Chemotherapy-induced acute toxicities in both arms were assessed weekly.

\section{RESULTS}

There was a significant increase in the incidence of anaemia in weekly chemotherapy patients at $7^{\text {th }}$ week (28\% verse $10 \%, \mathrm{P}-$ value 0.022$)$ and neutropenic infection at $11^{\text {th }}$ week (28 \% verse $10 \%, \mathrm{P}$ - value 0.022$)$. There was a non-statistically significant increase in the incidence of leukopenia, thrombocytopenia and paraesthesia and myalgia in the weekly arm. There was a significant increase in the incidence of gastrointestinal toxicity like grade 3 stomatitis (at $4^{\text {th }}-$ week), nausea and vomiting (at $4^{\text {th }} 7^{\text {th }}$, and $11^{\text {th }}$ week $)$ in three weekly chemotherapy patients.

\section{CONCLUSIONS}

In this study, acute neurological and haematological toxicities were more in the weekly neoadjuvant chemotherapy arm and acute gastrointestinal toxicities were more in the three weekly neoadjuvant chemotherapy arm.

\section{KEYWORDS}

Acute Toxicity, Neoadjuvant Paclitaxel Chemotherapy, Locally Advanced Breast Malignancy.
Corresponding Author: Mrs. Smitha G. Raj, Assistant Professor, Department of Anatomy, Government T. D. Medical College, Alappuzha, Kerala, India. E-mail: achusnith605@gmail.com

DOI: $10.14260 /$ jemds $/ 2021 / 725$

How to Cite This Article: Chellappan N, Raj GS. Acute toxicity of paclitaxel based dose dense and conventional neoadjuvant chemotherapy in locally advanced female breast cancer patients. J Evolution Med Dent Sci 2021;10(41):3577-3581, 10.14260/jemds/2021/725

Submission 13-08-2021,

Peer Review 28-09-2021, Acceptance 04-10-2021,

Published 11-10-2021.

Copyright (C) 2021 Nonam Chellappan et al. This is an open access article distributed under Creative Commons Attribution License [Attribution 4.0 International (CC $B Y 4.0)]$ 


\section{BACKGROUND}

Surgery, chemotherapy, radiation, biological and hormonal therapies are the main treatments of breast cancer, ${ }^{1}$ Locally advanced breast cancer is a tumour without distant spread. ${ }^{2}$ It includes tumour that is more than $5 \mathrm{~cm}$ in size with regional lymphadenopathy, or skin / the chest wall infiltration, or both, or lymph nodes at supraclavicular, axillary, infraclavicular or internal mammary area. Patients receiving chemotherapy before radical surgery is called neoadjuvant chemotherapy. Now anthracycline and taxanebased neoadjuvant treatment is recommended for locally advanced breast malignancy patients. ${ }^{3,4,5}$ Paclitaxel is the first taxane that exerts cytotoxicity by promoting tubulin polymerization. Peripheral neuropathy, joint pain and myalgia, infections (febrile neutropenia), anaemia, thrombocytopenia, hair loss, hypersensitivity reaction, stomatitis, vomiting and diarrhea ${ }^{5}$ are the adverse effects of paclitaxel. Weekly paclitaxel $80-100 \mathrm{mg} / \mathrm{m}^{2}$ neoadjuvant chemotherapy has more complete pathological reduction than every 3-weekly paclitaxel $\left[175 \mathrm{mg} / \mathrm{m}^{2}\right]$ chemotherapy in locally advanced breast malignancy patients. $6,7,8,9,10$

Anthracyclines (doxorubicin and epirubicin) are antibiotics. Bone marrow suppression, hyperpigmentation of skin and nails, loss of hair, vomiting, diarrhoea, hepatic impairment etc., ${ }^{11}$ are the adverse effect of anthracyclines.

\section{Objectives}

1. To assess the acute toxicities of three weekly and weekly neoadjuvant paclitaxel chemotherapies in locally advanced breast malignancy of female patients

2. To compare the acute toxicities between the two neoadjuvant paclitaxel chemotherapy patients.

\section{METHODS}

It is an observational comparative study involving 50 breast malignancy patients from the Department of Radiotherapy, Medical college, Thiruvananthapuram from 01/01 2011 to $30 / 11 / 2012$ for a period of 23 months.

\section{Inclusion Criteria}

Patients with

1. Locally advanced female breast cancer and age between 25 and 60 yrs.

2. Biopsy proven breast malignancy

3. Hb-(more than or equal to $10 \mathrm{gm} \% / \mathrm{dl}$ ), WBC count $\left(4 \times 10^{3}-11 \times 10^{3} / \mathrm{mm}^{3}\right)$, platelet count $\left(5 \times 10^{4}-30 \times 10^{4} /\right.$ $\mathrm{mm}^{3}$ ),

4. Normal liver and renal function test.

\section{Exclusion Criteria}

1. Patients with a history of early malignancy management.

2. Patients with a history of heart failure, hepatic disease, renal disease, and diabetes mellitus.

3. Patients with metastasis, ulcerative and inflammatory breast cancer.
4. Patients with poor performance status.

5. Patients with age more than 60 years.

6. Pregnant breast cancer patients.

Premedication (steroid and antihistamine) and antiemetics were given prior to paclitaxel infusion. Neoadjuvant chemotherapy-induced acute toxicities in both arms were assessed weekly and compared on $1^{\text {st }}, 4^{\text {th }}, 7^{\text {th }}$, and $11^{\text {th }}$ week by interview, general and systemic examination. There was no dose reduction in both arms during this study.

Incidence of anaemia, leukopenia, thrombocytopenia was assessed by blood investigation done every week. Grade of acute toxicity was assessed by World Health Organisation Toxicity Criteria. Anaemia was corrected by blood transfusion, neutropenia corrected by a granulocytic stimulating factor and neutropenia infection was treated with antibiotics, antifungal etc. Gastrointestinal symptoms were corrected by intravenous fluids, antiemetics, and antidiarrhoeal drugs.

Ethical committee approval was obtained before starting this study. All data were analysed by using SPSS statistical software.

\section{RESULTS}

\begin{tabular}{|c|c|c|c|c|}
\hline & \multirow{2}{*}{$\begin{array}{l}\text { Clinical and } \\
\text { Biographical } \\
\text { Information }\end{array}$} & \multicolumn{2}{|c|}{ Category } & \multirow{2}{*}{$\begin{array}{c}\text { Total } \\
\text { Number }\end{array}$} \\
\hline & & $\begin{array}{c}3 \text { Weekly } \\
\text { Number }\end{array}$ & $\begin{array}{l}\text { Weekly } \\
\text { Number }\end{array}$ & \\
\hline \multirow{3}{*}{ Stage } & $3 a$ & 28 & 30 & 58 \\
\hline & $3 b$ & 14 & 12 & 26 \\
\hline & $3 c$ & 8 & 8 & 16 \\
\hline \multirow{2}{*}{ Age } & $\leq 50$ years & 28 & 29 & 57 \\
\hline & $\geq 50$ years & 22 & 21 & 43 \\
\hline \multirow{4}{*}{ Parity } & Null parity & 1 & 3 & 4 \\
\hline & 1 child & 5 & 7 & 12 \\
\hline & 2 children & 38 & 37 & 75 \\
\hline & 3 children & 6 & 3 & 9 \\
\hline \multirow{2}{*}{$\begin{array}{l}\text { Menopause } \\
\text { status }\end{array}$} & Premenopause & 12 & 14 & 26 \\
\hline & Post menopause & 38 & 36 & 74 \\
\hline
\end{tabular}

Incidence of grade 1 anaemia developed after $1^{\text {st }}$ week of chemotherapy in three weekly patients. Incidence of grade 2 and 3 anaemia and leucopenia was more in weekly patients and grade 3 anaemia developed earlier (after $4^{\text {th }}$ week of chemotherapy) in weekly patients. Incidence of grade 4 leucopenia developed after $7^{\text {th }}$ week of chemotherapy in weekly patients. There was no incidence of grade 4 leucopenia in three weekly patients. Incidence of thrombocytopenia was more in weekly patients arm. Incidence of grade 3 thrombocytopenia developed after $7^{\text {th }}$ week of chemotherapy only in weekly patients. No patients had grade 4 thrombocytopenia in both arms.

\section{Anaemia}

There was a marked increase in the percentage of incidence of anaemia after the $1^{\text {st }}$ week of chemotherapy, which was more in the weekly patients. There was a statistically significant difference in the percentage of incidence of anaemia at $7^{\text {th }}$ week between two-arms $(28 \%$ verse $10 \%$, Pvalue 0.022 ) 
Hundred locally advanced female breast malignancy patients.

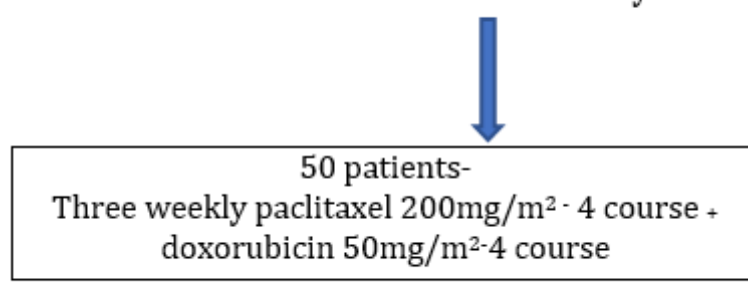

Total cumulative dose

Paclitaxel $-200 \mathrm{mg} / \mathrm{m}^{2} \times 4=800 \mathrm{mg} / \mathrm{m}^{2}$

Doxorubicin $-0 \mathrm{mg} / \mathrm{m}^{2} \times 4=200 \mathrm{mg} / \mathrm{m}^{2}$

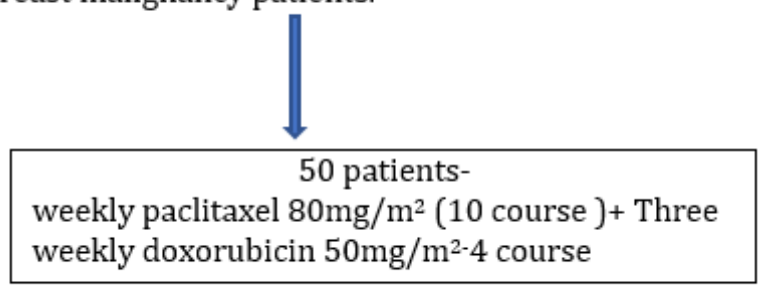

Total cumulative dose

Paclitaxel-80mg $/ \mathrm{m}^{2} \times 10=800 \mathrm{mg} / \mathrm{m}^{2}$

Doxorubicin- $50 \mathrm{mg} / \mathrm{m}^{2} \times 4=200 \mathrm{mg} / \mathrm{m}^{2}$

\author{
After four weeks. \\ All patients underwent \\ Modified radical mastectomy, \\ After two weeks \\ Adjuvant three weekly chemotherapy
}

(FAC fluorocuracil $500 \mathrm{mg} / \mathrm{m}^{2}$, doxorubicin $50 \mathrm{mg} / \mathrm{m}^{2}$ cyclophosphamide $500 \mathrm{mg} / \mathrm{m}^{2}$ four course),

External beam radiotherapy dose of $50 \mathrm{GY}$ in 25 fraction,

Adjuvant hormone therapy (Receptor status positive).

\title{
Study procedure
}

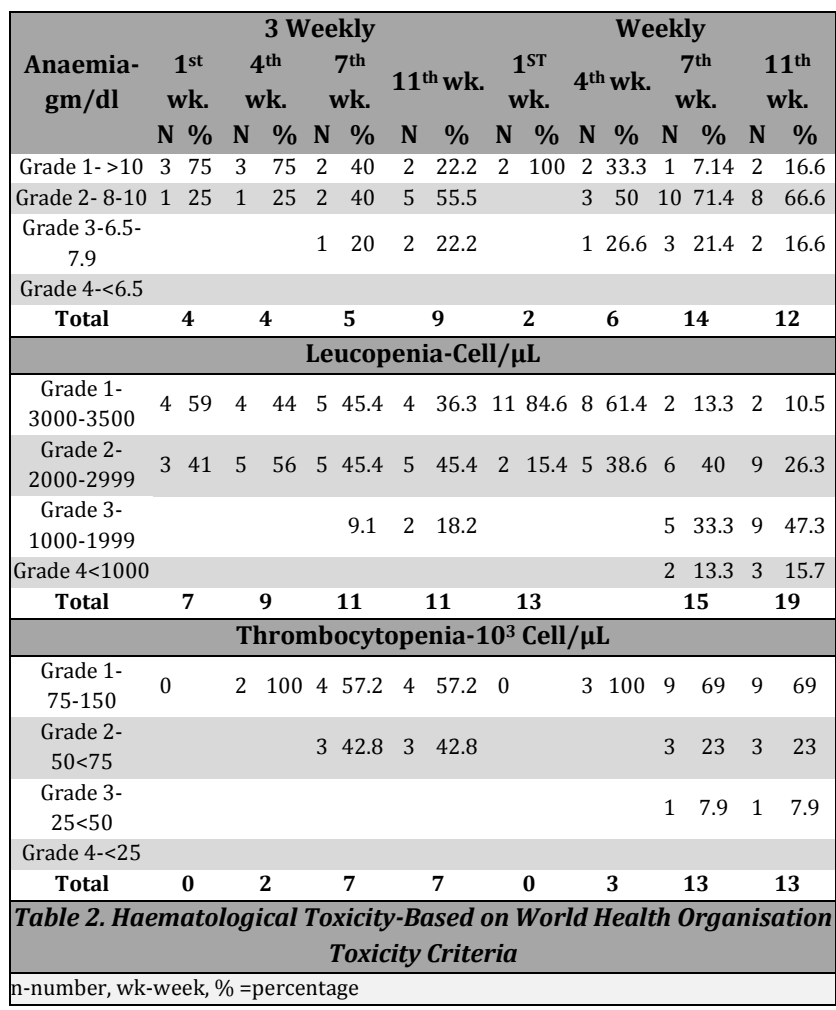

\begin{tabular}{|c|c|c|c|c|c|c|}
\hline \multirow{3}{*}{ Weeks } & \multirow{3}{*}{$\begin{array}{l}\text { Haematological } \\
\text { Toxicity }\end{array}$} & \multicolumn{4}{|c|}{ Category } & \multirow{3}{*}{$\mathbf{P}$} \\
\hline & & \multicolumn{2}{|c|}{3 Weekly } & \multicolumn{2}{|c|}{ Weekly } & \\
\hline & & Number & $\%$ & Number & $\%$ & \\
\hline \multirow{3}{*}{$1^{\text {st }}$} & Anaemia & 4 & 8 & 2 & 4 & 0.400 \\
\hline & Leucopenia & 7 & 14 & 13 & 26 & 0.134 \\
\hline & Thrombocytopenia & 0 & 0 & 0 & 0 & \\
\hline \multirow{3}{*}{$4^{\text {th }}$} & Anaemia & 4 & 8 & 6 & 12 & 0.505 \\
\hline & Leucopenia & 11 & 22 & 13 & 26 & 0.640 \\
\hline & Thrombocytopenia & 2 & 4 & 3 & 6 & 0.646 \\
\hline \multirow{3}{*}{$7^{\text {th }}$} & Anaemia & 5 & 10 & 14 & 28 & 0.022 \\
\hline & Leucopenia & 11 & 22 & 15 & 30 & 0.362 \\
\hline & Thrombocytopenia & 7 & 14 & 13 & 26 & 0.134 \\
\hline \multirow{3}{*}{$11^{\text {th }}$} & Anaemia & 9 & 18 & 12 & 24 & 0.461 \\
\hline & Leucopenia & 11 & 22 & 19 & 38 & 0.081 \\
\hline & Thrombocytopenia & 7 & 14 & 13 & 26 & 0.134 \\
\hline
\end{tabular}

\section{Leucopenia}

$26 \%$ of patients had an incidence of leucopenia at $1^{\text {st }}$ and $4^{\text {th }}$ week in the weekly arm; further incidence of leucopenia was seen after the $7^{\text {th }}$ week in the weekly arm. But in three weekly arms, incidence of leucopenia increased at $1^{\text {st, }} 4^{\text {th }}$ and $7^{\text {th }}$ week and no further increase in incidence. The incidence of leucopenia was more in weekly patients.

\section{Thrombocytopenia}

There was no incidence of thrombocytopenia at $1^{\text {st }}$ week in both arms. But in three weekly arms, incidence of thrombocytopenia did not increase after the $7^{\text {th }}$ week. The incidence of thrombocytopenia was more in weekly patients.

\section{At the End of First Week}

Percentage of incidence of anaemia ( $8 \%$ vs. $4 \%$ ) was more in three weekly arms and leucopenia ( $14 \%$ vs. $26 \%$ ) was more in patients in the weekly arm. There were no patients with thrombocytopenia.

\section{At the End of Fourth Week}

Percentage of incidence of anaemia (12 \% vs. $8 \%$ ), leucopenia, $26 \%$ vs. $22 \%$ ) and thrombocytopenia $6 \%$ vs. 4 $\%$ ) was increased in patients in both arms, more in the weekly arm. There was no increase in the incidence of leucopenia in the weekly arm. The percentage of incidence of patients with thrombocytopenia was more in patients in the weekly arm than in the three-weekly arm (6\% vs. $4 \%$ ).

\section{At the End of Seventh Week}

There was a statistically significant increased incidence of anaemia in the weekly patients (28\% vs. $10 \%$ ), ( $\mathrm{P}$ - value 0.022). The percentage of incidence of leucopenia was 
increased more in weekly patients (30 \% vs. $22 \%$ ). Percentage of incidence of thrombocytopenia was more in weekly patients ( $26 \%$ vs. $14 \%$ ).

\begin{tabular}{|c|c|c|c|c|c|c|c|c|c|c|c|c|c|}
\hline \multirow{4}{*}{ No. } & \multirow{4}{*}{$\begin{array}{c}\text { Acute } \\
\text { Toxicity } \\
\text { of } \\
\text { Paclitaxel }\end{array}$} & \multicolumn{3}{|c|}{$1^{\text {st }-W e e k s}$} & \multicolumn{3}{|c|}{$4^{\text {th }}-$ Week } & \multicolumn{3}{|c|}{$7^{\text {th-Week }}$} & \multirow{2}{*}{\multicolumn{3}{|c|}{$\begin{array}{l}1^{\text {th }} \text {-Week } \\
\text { Patients }\end{array}$}} \\
\hline & & Pati & ents & $P$ & Pati & ents & P I & Pati & ents & $\mathbf{S} \mathbf{P}$ & & & \\
\hline & & $\begin{array}{c}3 \\
\text { wk }\end{array}$ & wk & & $\begin{array}{c}3 \\
\text { wk }\end{array}$ & wk & & $\begin{array}{c}3 \\
\text { wk }\end{array}$ & wk & & $\begin{array}{c}3 \\
\text { wk }\end{array}$ & wk & $P$ \\
\hline & & $\mathbf{N}$ & $\mathbf{N}$ & & $\mathbf{N}$ & $\mathbf{N}$ & & $\mathbf{N}$ & $\mathbf{N}$ & & $\mathbf{N}$ & $\mathbf{N}$ & \\
\hline 1 & $\begin{array}{l}\text { Neutropenic } \\
\text { fever }\end{array}$ & 7 & 13 & 0.134 & 11 & 13 & 0.640 & 011 & 15 & 0.362 & 211 & 19 & 0.081 \\
\hline 2 & $\begin{array}{l}\text { Neutropenic } \\
\text { infection }\end{array}$ & 4 & 2 & 0.400 & 4 & 6 & 0.505 & 59 & 12 & 0.461 & 15 & 14 & 0.022 \\
\hline 3 & $\begin{array}{c}\text { Non- } \\
\text { Neutropenic } \\
\text { infection }\end{array}$ & 0 & 3 & 0.079 & 1 & 3 & 0.307 & 72 & 1 & 0.558 & 83 & 1 & 0.307 \\
\hline 4 & $\begin{array}{c}\text { Myalgia } \\
=\text { grade }-1\end{array}$ & 16 & 10 & 0.171 & 20 & 11 & 0.052 & 224 & 16 & 0.102 & 227 & 24 & 0.548 \\
\hline 5 & $\begin{array}{c}\text { Myalgia } \\
=\text { grade- } 2\end{array}$ & 0 & 4 & 0.076 & 9 & 5 & 0.249 & 911 & 10 & 0.806 & 615 & 18 & 0.523 \\
\hline 6 & $\begin{array}{c}\text { Myalgia= } \\
\text { grade-3 }\end{array}$ & 0 & 0 & & 2 & 3 & 0.646 & 67 & 5 & 0.538 & 810 & 12 & 0.629 \\
\hline 7 & $\begin{array}{c}\text { stomatitis= } \\
\text { grade-3 }\end{array}$ & 9 & 2 & 0.025 & 13 & 4 & 0.017 & 711 & 6 & 0.183 & 313 & 8 & 0.220 \\
\hline 8 & $\begin{array}{l}\text { Nausea } \\
=\text { grade- } 3\end{array}$ & 16 & 8 & 0.061 & 30 & 12 & 0.001 & 136 & 12 & 0.000 & 042 & 21 & 0.000 \\
\hline 9 & $\begin{array}{l}\text { Vomiting } \\
=\text { grade- } 3\end{array}$ & 12 & 7 & 0.202 & 21 & 9 & 0.009 & 928 & 12 & 0.001 & 136 & 22 & 0.005 \\
\hline 10 & $\begin{array}{l}\text { Diarrhoea } \\
=\text { grade- } 3\end{array}$ & 3 & 0 & 0.079 & 5 & 2 & 0.240 & 07 & 4 & 0.338 & 89 & 5 & 0.249 \\
\hline 11 & $\begin{array}{l}\text { Paraesthesia } \\
=\text { grade- } 3\end{array}$ & 6 & 7 & 0.766 & 11 & 12 & 0.813 & 317 & 22 & 0.305 & 531 & 35 & 0.398 \\
\hline \multicolumn{14}{|c|}{ Table 4. Acute Toxicity of Paclitaxel } \\
\hline & wk-w & & & & & & & & & & & & \\
\hline
\end{tabular}

\section{At the End of Eleventh Week}

The percentage of incidence of anaemia was decreased in patients in the weekly arm (28\% to $24 \%$ ) and it increased in the three-weekly arm (10\% to $18 \%)$. Patients had more percentage of incidences of leucopenia in the weekly arm (38 $\%$ vs. $22 \%$ ). There was no increase in the percentage of incidence of leucopenia in the three-weekly arm. Percentage of incidence of patients with thrombocytopenia is the same as in the seventh week in both arms (26\% vs. $14 \%$ ).

Percentage of incidence of neutropenic fever and neutropenic infection increased in both arms. After the $4^{\text {th }}$ week, the incidence of neutropenic fever increased in weekly patients and it was not increased in three weekly patients. In the $11^{\text {th }}$ week, incidence of neutropenic infection was more in weekly patients (28\% vs. $10 \%)(P=0.022)$, that was statistically significant. Incidence of non-neutropenic infection was less than neutropenic infection in both arms. Incidence of non-neutropenic infection increased as completing each cycle in three weekly arms.

The percentage of incidence of chemotherapy-induced myalgia increased after every chemotherapy cycle in patients in both arms. Percentage of incidence of grade 1 myalgia was more in the three-weekly arm (54\% vs. $48 \%$ ) at $11^{\text {th }}$ week. but the incidence of severe (grade 2 and 3) myalgia was more in patients in the weekly arm, mainly after $3^{\text {rd }}$ and $4^{\text {th }}$ cycles. Incidence of gastrointestinal toxicities like grade 3 stomatitis, nausea, vomiting, and diarrhoea increased after every chemotherapy cycle in patients in both arms, but more in three weekly patients. That is significant statistically. Percentage of incidence of paraesthesia increased in both chemotherapy arms as advancing each chemotherapy cycle. It was increased more in weekly patients. Loss of hair in all patients, blackish discolouration of nail bed were seen in most of the patients in both arms. $60 \%$ of premenopausal patients in weekly arms and $50 \%$ premenopausal patients in three weekly arms had ceased their menstruation during chemotherapy.

\section{DISCUSSION}

Neoadjuvant chemotherapy was first used in locally advanced breast cancer patients. All anticancer therapy causes adverse effects, so oncologists continue to search new methods of treatments that can produce a high response with less severity and incidence of adverse effects. In node-positive patients, three weekly paclitaxel and anthracycline showed more overall and disease-free survival12-14 with weekly paclitaxel having more overall survival advantages. ${ }^{15}$ Peripheral neuropathy is the commonest toxicity of paclitaxel.16,17 The high-dose weekly paclitaxel schedule in Marjorie C. Green ${ }^{15}$ study showed a better response with higher toxicity. But the chemotherapy toxicity was short duration to permit surgery rapidly after best response. In the CALGB 9840 trial, $^{18}$ in metastatic breast cancer patients weekly paclitaxel had higher grade 3 neuropathy (24 vs. 12 $\%, P=0.0003$ ). In non-metastatic breast cancer, Praveen Kumar Shenoy trial showed that weekly paclitaxel chemotherapy alone or combination had more acute toxicities. ${ }^{19}$ In postoperative breast cancer, Sparano et al. ${ }^{20}$ studies show that weekly paclitaxel patients had higher grade neuropathy and three weekly patients had higher grade arthralgia, myalgia and neutropenia.

In our study, percentage of incidence of anaemia (28\%), leucopenia (38\%), thrombocytopenia (26\%), neutropenic fever (38\%), neutropenic infection (28\%) and paraesthesia $(70 \%)$ were more in patients in the weekly arm than three weekly arms. Percentage of incidence of stomatitis (26), nausea (84\%), vomiting (72\%), diarrhoea (18\%) and myalgia (54\%) were more in patients in three weekly arms than a weekly arm. Comparison of anaemia between the two groups, after $1^{\text {st }}$ week incidence of anaemia more in the three-weekly arm, but later (after $4^{\text {th }}$ week) the percentage of anaemia was more in the weekly regimen (maximum $28 \%$ ) as compared to three regimens (maximum $18 \%$ ). Leucopoenia was more in weekly regimen (maximum $38 \%$ ) than 3 weekly (maximum $22 \%$ ). Patients with anaemia on weekly regimen progressed to grade 3 more than three weekly arm (12\% verse $6 \%$ ). The differences in incidence of anaemia were statistically significant in the $7^{\text {th }}$ week ( $p$ 0.022 ). There is no statistically significant difference in percentage of increase in incidence thrombocytopenia between two arms. Grade 3 and 4 neutropenia was more common in patients receiving weekly regimen. There was statistically significant more incidence of nausea and vomiting in three weekly patients (at $4^{\text {th }} 7^{\text {th }}$, and $11^{\text {th }}$-weeks) and grade 3 stomatitis (at $4^{\text {th }}$ - weeks). There was no dose reduction done in both arms during this study.

In Marjorie c. Green ${ }^{15}$ study showed that chemotherapy related toxicities, [stomatitis- grade 3 (24 \% vs. $0 \%$ ), vomiting, grade 3 (1\% vs. $0 \%$ ) diarrhoea, grade 3,- (5.5\% vs. $5.3 \%$ )], neurological toxicities (paraesthesia - $38 \%$ vs. $23 \%$ ) neutropenic infection ( 9.5 vs. $1 \%$ ) myalgias (29 \% vs. $19 \%$ ) were more in three weekly patients than weekly patients. Haematological toxicities were very less in both arms (dose modification done to reduce the incidence). $25 \%$ weekly 
paclitaxel dose was reduced in patients with higher grade neurotoxicity and $20 \%$ weekly paclitaxel dose was reduced in patients with higher grade nonhematological toxicity 15 (National Cancer Institute toxicity criteria version 2.0)

\section{CONCLUSIONS}

Patients with locally advanced malignancy of breast were previously treated with surgery, palliative chemotherapy and radiation. Prognosis was very poor and malignancy finally spread to other sites. Long-term survival has been greatly improved with aggressive treatment with the use of neoadjuvant chemotherapy. Weekly neoadjuvant paclitaxel in locally advanced malignancy of breast shows high pathological complete response rates and different toxicity profile. Acute neurological toxicities and haematological toxicities were more in weekly chemotherapy patients. Gastrointestinal toxicities were more in three weekly chemotherapy patients.

Data sharing statement provided by the authors is available with the full text of this article at jemds.com.

Financial or other competing interests: None.

Disclosure forms provided by the authors are available with the full text of this article at jemds.com.

\section{REFERENCES}

[1] DePinho RA, Weinberg RA, DeVita VT, et al. Devita, Hellman \& Rosenberg's cancer: principles \& practice of oncology. $8^{\text {th }}$ edn. Wolters Kluwer 2008.

[2] Rowinsky EK, Donehower RC. Paclitaxel (taxol). N Engl J Med 1995;332(15):1004-14.

[3] De Lena M, Zucali R, Viganotti G, et al. Combined chemotherapy-radiotherapy approach in locally advanced $\left(\mathrm{T}_{3 \mathrm{~b}}-\mathrm{T}_{4}\right)$ b breast cancer. Cancer Chemother Pharmacol 1978;1(1):53-9.

[4] Sikov WM, Akerley W, Cummings F, et al. Weekly highdose paclitaxel in locally advanced breast cancer: a preliminary report. Semin Oncol 1997;(5 Suppl 17):S1787-S17-90.

[5] Chu E, DeVita VT. Physicians cancer chemotherapy drug manual 2012. $12^{\text {th }}$ edn. Jones and Bartlett Publishers Inc 2011.

[6] Sparano JA. Taxanes for breast cancer: an evidencebased review of randomized phase II and phase III trails. Clin Breast Cancer 2000;1(1):32-40.

[7] Winer EP, Berry DA, Woolf S, et al. Failure of higher dose paclitaxel to improved outcome in patients with metastatic breast cancer: cancer and leukemia group B trail 9342. J Clin Oncol 2004;22(11):2061-8.

[8] Green MC, Buzdar AU, Smith T et al. Weekly (wkly) paclitaxel (P) followed by FAC as primary systemic chemotherapy (PSC) of operable breast cancer improves pathologic complete remission (pCR) rates when compared to every 3-week (Q 3 wk) P therapy (tx) followed by FAC-final results of a prospective phase III randomized trial. Proc Am Soc Clin Oncol 2002;21:135.

[9] Bear HD. Indications for neoadjuvant chemotherapy for breast cancer. Semin Oncol 1998;25(2 Suppl 3):3-12.

[10] Hortobagyi GN. Comprehensive management of locally advanced breast cancer. Cancer 1990;66(6 Suppl):138791.

[11] Del Gaudio D, Menonna-Quinn D. Chemotherapy. Potential occupational hazards. Am J Nurs 1998;98(11):59-65.

[12] Henderson IC, Berry DA, Demetri GD, et al:. Improved outcomes from adding sequential paclitaxel but not from escalating doxorubicin dose in adjuvant chemotherapy regimen for patients with node-positive primary breast cancer. J Clin Oncol 2003;21(6):976-83.

[13] Citron ML, Berry DA, Cirrincione C, et al. Randomized trial of dose-dense versus conventionally scheduled and sequential versus concurrent combination chemotherapy as postoperative adjuvant treatment of node-positive primary breast cancer: first report of Intergroup Trial C9741/Cancer and Leukemia Group B Trial 9741. J Clin Oncol 2003;21(8):1431-9.

[14] Buzdar AU, Singletary SE, Valero V, et al. Evaluation of paclitaxel in adjuvant chemotherapy for patients with operable breast cancer: preliminary data of a prospective randomized trial. Clin Cancer Res 2002;8:1073-1079.

[15] Green MC, Buzdar AU, Smith T, et al. Weekly paclitaxel improves pathologic complete remission in operable breast cancer when compared with paclitaxel once every 3 weeks. J Clin Oncol 2005;23(25):5983-92.

[16] Al-Mahayri ZN, AlAhmad MM, Ali BR. Current opinion on the pharmacogenomics of paclitaxel-induced toxicity. Expert Opin Drug Metab Toxicol 2021;17(7):785-801.

[17] Hertz DL. Exploring pharmacogenetics of paclitaxel- and docetaxel-induced peripheral neuropathy by evaluating the direct pharmacogenetic-pharmacokinetic and pharmacokinetic-neuropathy relationships. Expert Opin Drug Metab Toxicol 2021;17(2):227-39.

[18] Seidman AD, Berry D, Cirrincione C, et al Randomized phase III trial of weekly compared with every-3-weeks paclitaxel for metastatic breast cancer, with trastuzumab for all HER-2 overexpressors and random assignment to trastuzumab or not in HER-2 nonoverexpressors: final results of Cancer and Leukemia Group B protocol 9840. J Clin Oncol 2008;26(10):1642-9.

[19] Shenoy PK, Ebrahim I, Skaria AM, et al. Toxicity profile of weekly regimen of paclitaxel in patients with nonmetastatic breast cancer-a real world experience. Oncol Radiotherapy 2021;15(2):009-012.

[20] Sparano JA, Wang M, Martino S, et al. Weekly paclitaxel in the adjuvant treatment of breast cancer. N Engl J Med 2008;358(16):1663-71. 